\title{
IMPLEMENTASI ALGORITMA K-MEANS UNTUK DIAGNOSA PENYAKIT GAGAL GINJAL KRONIS
}

\author{
Hervisari' ${ }^{1}$ S. Musdalifah² dan I W. Sudarsana ${ }^{3}$ \\ 1,2,3 Program Studi Matematika Jurusan Matematika FMIPA Universitas Tadulako \\ Jalan Soekarno-Hatta Km. 09 Tondo, Palu 94118, Indonesia. \\ 1vhervisari@gmail.com, 2Selvymusdalifah@yahoo.com, 33sudarsanaiwayan@yahoo.co.id
}

\begin{abstract}
Chronic Kidney Desease (CKD) is a medical, social dan economical problems for patients and their family. It becomes complex problem especially in developing countries which have limited source to cost for Chronic Kidney Desease patients. CKD's patient increased every year due to delay in diagnosis, the patient has died of complications prior to diagnosis. Therefore we need an action to anticipate the number of patients with CKD. In this research, K-Means algorithm is implemented to diagnose CKD. The result will be used in diagnosis process. The result are two cluster, each cluster consisting of chronic condition and the other ones can be recovered.
\end{abstract}

Keywords $\quad$ : Algorithm K-means, Chronic Kidney Desease (CKD), Cluster, Diagnosis

\section{ABSTRAK}

Gagal Ginjal Kronis (GGK) merupakan masalah medik, sosial dan ekonomi bagi pasien dan keluarganya. Hal ini menjadi masalah yang besar khususnya di negara-negara yang sedang berkembang dan memiliki sumbersumber terbatas untuk membiayai pasien dengan gagal ginjal kronis. Jumlah penderita GGK terus meningkat tiap tahunnya, hal ini disebabkan karena keterlambatan penegakkan diagnosis tersebut. Pasien sudah meninggal akibat komplikasi sebelum adanya penegakkan diagnosis. Oleh karena itu diperlukan suatu tindakan guna mengantisipasi jumlah penderita GGK. Dalam penelitian ini, diimplementasikan algoritma K-Means untuk mendiagnosa penyakit gagal ginjal kronis menggunakan K-Means cluster. Hasil hitung dari K-Means cluster akan digunakan dalam proses mendiagnosa. Dataset yang digunakan dalam proses uji coba menghasilkan dua buah cluster, yang masing-masing cluster terdiri dari pasien yang menderita gejala dan penyebab dengan diagnosa parah dan pasien yang masih dapat disembuhkan.

Kata Kunci : Algoritma K-Means, Cluster, Diagnosa, Gagal Ginjal Kronis

\section{PENDAHULUAN}

Gagal ginjal kronis biasanya akibat akhir dari kehilangan fungsi ginjal lanjut secara bertahap. Gagal ginjal kronis terjadi bila ginjal sudah tidak mampu mempertahankan lingkungan internal yang 
konsisten dengan kehidupan dan pemulihan fungsi tidak dimulai. Pada kebanyakan individu transisi dari sehat ke status kronis atau penyakit yang menetap sangat lamban dan menunggu beberapa tahun (Doenges, 1999; 626).

Umumnya GGK disebabkan oleh penyakit ginjal intrinsik difus dan menahun. Glomerulonefritis, hipertensi esensial dan pielonefritis merupakan penyebab paling sering dari gagal ginjal kronik, kira-kira 60\%. 47\% penderita gagal ginjal kronis yang berusia lebih dari 60 tahun lebih banyak disebabkan karena gangguan metabolik seperti diabetes melitus. Berdasarkan data USRDS tahun 2000 , hipertensi merupakan penyebab ESRD yang paling besar, yaitu sebanyak $21 \%$ dari total kasus (Sukandar, 2006).

Peningkatan jumlah gagal ginjal disebabkan keterlambatan penegakkan diagnosis penyakit tersebut. Pasien sudah meninggal akibat komplikasi sebelum ada nya penegakan diagnosis (Sudoyo. dkk, 2006). Penyebab keterlambatan penegakkan diagnosis tersebut adalah banyaknya faktor yang berpengaruh terhadap pilihan-pilihan yang ada atau beragamnya variabel. Algortima K-Means dengan metode clustering merupakan salah satu solusi untuk mengatasi masalah tersebut. Algoritma K-Means dimulai dengan pemilihan secara acak $\mathrm{K}, \mathrm{K}$ disini merupakan banyaknya cluster yang ingin dibentuk. Kemudian tetapkan nilai-nilai $\mathrm{K}$ secara random, untuk sementara nilai tersebut menjadi pusat dari cluster atau biasa disebut dengan centroid, mean atau "means". Hitung jarak setiap data yang ada terhadap masing-masing centroid menggunakan rumus Euclidian hingga ditemukan jarak yang paling dekat dari setiap data dengan centroid. Klasifikasikan setiap data berdasarkan kedekatannya dengan centroid. Lakukan langkah tersebut hingga nilai centroid tidak berubah (stabil) (Santosa,2007). Langkah-langkah dalam algoritma K-Means clustering adalah :

1. Menentukan jumlah cluster.

2. Menentukan nilai centroid.

3. Menghitung jarak antara titik centroid dengan titik tiap objek. Untuk menghitung jarak tersebut dapat menggunakan euclidean distance. Adapun rumusnya adalah sebagai berikut

$D(x, y)=\sqrt{\sum_{i=1}^{n}\left\|x_{i}-y_{i}\right\|^{2}}$

Keterangan :

- D adalah euclidean distance

- $\quad i=1,2, \ldots, n$ adalah banyaknya dimensi

- $\quad(x, y)$ adalah koordinat objek

Dari perhitungan jarak diatas, cara penggunaannya adalah memasukkan sebuah objek ke dalam cluster tertentu dengan mengukur 'jarak' objek tersebut dengan pusat cluster. Jika data ada dalam jarak yang masih dalam batas tertentu ( mendekati nilai yang lebih kecil) 
maka data tersebut dapat dimasukkan pada cluster sedemikian hingga jarak tiap-tiap objek ke pusat kelompok di dalam satu kelompok adalah minimum.

4. Kembali ke tahap 2, lakukan perulangan hingga nilai titik tengah yang di hasilkan tetap dan anggota cluster tidak berpindah-pindah ke cluster lain.

\section{METODE PENELITIAN}

Berikut adalah penjelasan dari tahapan penelitian yang akan dilakukan penyusun dalam proses penelitian :

1. Memulai Penelitian.

2. Melakukan studi literatur dengan mengumpulkan materi dari buku-buku, jurnal atau artikel yang di dapat dari perpustakaan dan perpustakaan online.

3. Mengkonfirmasi ke Dokter mengenai gejala penyakit yang akan diteliti.

4. Menentukan diagnosa gejala penyakit gagal ginjal kronis menggunakan metode algoritma K-Means.

5. Mengelompokkan objek berdasarkan jarak minimum.

6. Memperoleh hasil diagnosa.

III. HASIL DAN PEMBAHASAN

\subsection{HASIL}

Bab ini menjelaskan tahap-tahap untuk menentukan diagnosa gejala penyakit gagal ginjal kronis menggunakan metode algoritma K-Means. Dengan asumsi yang diberikan jika,

1. Nilai dari suatu gejala $\geq 3$ maka diagnosa yang dilakukan untuk penyakit gagal ginjal termasuk parah dan tidak dapat disembuhkan lagi.

2. Nilai dari suatu gejala $<3$ maka diagnosa yang dilakukan untuk penyakit gagal ginjal termasuk tidak terlalu parah atau masih dapat di sembuhkan.

\subsubsection{Mengkonfirmasi Gejala-Gejala Penyakit}

Dari hasil wawancara dengan Spesialis Penyakit Dalam RSUD Undata Palu dr. Rustam Amirudin Sp. PD pada tahun 2013, diperoleh 10 gejala yang menjadi faktor penyebab terjadinya resiko. Yaitu, merasa mual berakhir muntah-muntah, berkurangnya kandungan urine saat buang air kecil, merasa lelah dan lemah karena penurunan hemoglobin, hilangnya nafsu makan, menurunnya mental secara signifikan, mempunyai masalah dengan tidur, munculnya rasa gatal, otot kejang dan berkedut, mengalami bengkak pada area kaki, betis dan area yang tidak biasanya dan tekanan darah meningkat karena kelebihan cairan. 


\subsubsection{Flowchart Algoritma K-Means}

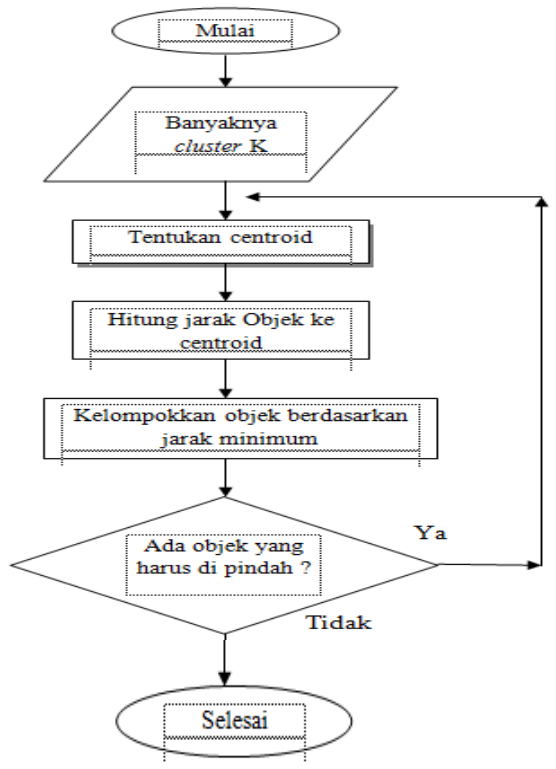

\subsubsection{Pengambilan Data}

Setelah mengkonfirmasi kedokter mengenai gejala dan penyebab terjadinya penyakit gagal ginjal kronis, selanjutnya mengadakan wawancara langsung dengan dokter spesialis penyakit dalam yang menangani penyakit tersebut. Hasil wawancara yang diperoleh adalah sebagai berikut.

Tabel 1 : Data Umum Pasien yang Menderita GGK Tahun 2013

\begin{tabular}{|c|c|c|}
\hline Pasien & Gejala & Penyebab \\
\hline 1. & $\begin{array}{l}\text { - Berkurangnya kandungan Urine } \\
\text { - Hilangnya nafsu makan } \\
\text {-Mengalami bengkak pada area kaki } \\
\text { - Tekanan Darah tinggi }\end{array}$ & $\begin{array}{l}\text { - Batu ginjal } \\
\text { - Hipertensi }\end{array}$ \\
\hline 2. & $\begin{array}{l}\text { - Tekanan darah tinggi } \\
\text {-Mempunyai masalah dengan tidur } \\
\text { - Munculnya rasa gatal } \\
\text {-Mengalami bengkak pada area kaki } \\
\text { - Merasa mual }\end{array}$ & $\begin{array}{l}\text { - Hipertensi } \\
\text { - Insomnia } \\
\text { - Diabetes }\end{array}$ \\
\hline 3. & $\begin{array}{l}\text { - Berkurangnya kandungan urine } \\
\text { - Merasa lelah }\end{array}$ & $\begin{array}{l}\text { - Batu ginjal } \\
\text { - Lupus }\end{array}$ \\
\hline 4. & $\begin{array}{l}\text { - Munculnya rasa gatal } \\
\text { - Hilangnya nafsu makan } \\
\text { - Menurunnya mental } \\
\text { - Mengalami gangguan tidur }\end{array}$ & Lupus \\
\hline
\end{tabular}




\begin{tabular}{|l|l|l|}
\hline 5. & - Merasa mual & - Batu ginjal \\
& - Berkurangnya kandungan urine & - Diabetes \\
& - Hilangnya nafsu makan & - Lupus \\
\hline 6. & Bengkak pada area kaki & \\
\hline 7. & $\begin{array}{l}\text { - Hilangnya nafsu makan } \\
\text { - Mempunyai gangguan tidur }\end{array}$ & Batu ginjal \\
\hline 8. & - Tekanan darah tinggi & \\
\hline 9. & - Bengkak pada area kaki & - Hipertensi \\
& - Menurunnya mental & - Diabetes \\
\hline 10. & - Munculnya rasa gatal & - Lupus \\
\hline
\end{tabular}

Dari data di atas, kita memiliki 10 objek sebagai titik data pelatihan dan setiap obyek memiliki 2 atribut mewakili koordinat dari objek, yaitu :

Objek atribut $1(x)$ : Gejala

Objek atribut $2(y)$ : Penyebab

Tabel 2 : Data Kasus GGK tahun 2013

\begin{tabular}{|c|c|c|}
\hline Objek & Gejala $(x)$ & 2 \\
\hline Pasien A & 4 & 3 \\
\hline Pasien B & 5 & 2 \\
\hline Pasien C & 2 & 1 \\
\hline Pasien D & 4 & 1 \\
\hline Pasien E & 4 & 3 \\
\hline Pasien F & 1 & 1 \\
\hline Pasien G & 2 & 0 \\
\hline Pasien H & 2 & 2 \\
\hline Pasien I & 3 & 1 \\
\hline Pasien J & 1 & Penyebab $(y)$ \\
\hline
\end{tabular}

\subsubsection{Menentukan Pusat Clusterdan Jarak Data}

\section{Menentukkan jumlah cluster}

Dengan memperhatikan data tersebut, kita dapat mengelompokkan objek tersebut ke dalam dua cluster sesuai dengan atributnya (yaitu cluster 1 dan cluster 2). Dari data yang diperoleh, dapat ditentukan bahwa 10 objek tersebut 
memiliki 2 atribut (gejala dan penyebab), dimana tiap-tiap pasien mewakili satu titik dengan 2 atribut $(x, y)$.

\section{Menentukkan nilai centroid}

Untuk menentukan nilai awal centroid dilakukan secara acak. Disini, dimisalkan titik koordinat pasien A, B, C, D, E adalah cluster $1\left(C_{1}\right)$ dan pasien $\mathrm{F}, \mathrm{G}, \mathrm{H}, \mathrm{I}, \mathrm{J}$ adalah cluster $2\left(C_{2}\right)$ sebagai nilai centroid awal.

Tabel 3 : Centroid Awal

\begin{tabular}{|c|c|c|}
\hline Cluster & $\mathrm{X}_{1}$ & $\mathrm{X}_{2}$ \\
\hline$\{\mathrm{A}, \mathrm{B}, \mathrm{C}, \mathrm{D}, \mathrm{E}\}$ & $\frac{4+5+2+4+4}{5}=\frac{19}{5}$ & $\frac{2+3+2+1+3}{5}=\frac{11}{5}$ \\
\hline$\{\mathrm{F}, \mathrm{G}, \mathrm{H}, \mathrm{I}, \mathrm{J}\}$ & $\frac{1+2+2+3+1}{5}=\frac{9}{5}$ & $\frac{1+0+2+2+1}{5}=\frac{6}{5}$ \\
\hline
\end{tabular}

Sehingga centroid awal yang terbentuk untuk cluster berturut-turut adalah $C_{1}=$ $\left(\frac{19}{5}, \frac{11}{5}\right)$ dan $C_{2}=\left(\frac{9}{5}, \frac{6}{5}\right)$.

3. Menghitung jarak antara titik centroid dengan tiap titik objek.

Pada langkah ini, misalkan dengan menggunakan perhitungan kuadrat jarak Euclid, dihitung jarak setiap objek dari pusat cluster (centroid) dan memasukkan hasilnya kedalam cluster terdekat. Pada setiap pemindahan objek pada suatu cluster tertentu, $k$ rataannya harus dihitung kembali sebelum dilanjutkan keproses berikutnya. Perhitungan jaraknya sebagai berikut :

$d^{2}(A,\{A, B, C, D, E\})=\left(4-\frac{19}{5}\right)^{2}+\left(2-\frac{11}{5}\right)^{2}=(0,2)^{2}+(-0,2)^{2}=0,08$

$d^{2}(A,\{F, G, H, I, J\})=\left(4-\frac{9}{5}\right)^{2}+\left(2-\frac{6}{5}\right)^{2}=(2,2)^{2}+(0,8)^{2}=5,48$

Karena jarak A lebih dekat dengan cluster $\{A, B, C, D, E\}$ dari pada $\{F, G, H, I, J\}$, maka $A$ tidak perlu pindah dari cluster $\{A, B, C, D, E\}$.

$d^{2}(B,\{A, B, C, D, E\})=\left(5-\frac{19}{5}\right)^{2}+\left(3-\frac{11}{5}\right)^{2}=(1,2)^{2}+(0,8)^{2}=2,08$

$d^{2}(B,\{F, G, H, I, J\})=\left(5-\frac{9}{5}\right)^{2}+\left(3-\frac{6}{5}\right)^{2}=(3,2)^{2}+(1,8)^{2}=13,48$

Karena jarak $B$ lebih dekat dengan cluster $\{A, B, C, D, E\}$ dari pada $\{F, G, H, I, J\}$, maka $B$ tidak perlu pindah dari cluster $\{A, B, C, D, E\}$.

$d^{2}(C,\{A, B, C, D, E\})=\left(2-\frac{19}{5}\right)^{2}+\left(2-\frac{11}{5}\right)^{2}=(-1,8)^{2}+(-0,2)^{2}=3,28$
$d^{2}(C,\{F, G, H, I, J\})=\left(2-\frac{9}{5}\right)^{2}+\left(2-\frac{6}{5}\right)^{2}=(0,2)^{2}+(0,8)^{2}=0,68$

Karena jarak $C$ lebih dekat dengan cluster $\{F, G, H, I, J\}$ dari pada $\{A, B, C, D, E\}$, maka perlu ada pemindahan cluster $C$ ke cluster $\{F, G, H, I, J\}$. 
$d^{2}(D,\{A, B, C, D, E\})=\left(4-\frac{19}{5}\right)^{2}+\left(1-\frac{11}{5}\right)^{2}=(0,2)^{2}+(-1,2)^{2}=1,48$

$d^{2}(D,\{F, G, H, I, J\})=\left(4-\frac{9}{5}\right)^{2}+\left(1-\frac{6}{5}\right)^{2}=(2,2)^{2}+(-0,2)^{2}=4,88$

Karena jarak $D$ lebih dekat dengan cluster $\{A, B, C, D, E\}$ dari pada $\{F, G, H, I, J\}$, maka $D$ tidak perlu pindah dari cluster $\{A, B, C, D, E\}$.

$d^{2}(E,\{A, B, C, D, E\})=\left(4-\frac{19}{5}\right)^{2}+\left(3-\frac{11}{5}\right)^{2}=(0,2)^{2}+(0,8)^{2}=0,68$

$d^{2}(E,\{F, G, H, I, J\})=\left(4-\frac{9}{5}\right)^{2}+\left(3-\frac{6}{5}\right)^{2}=(2,2)^{2}+(1,8)^{2}=8,08$

Karena jarak $E$ lebih dekat dengan cluster $\{A, B, C, D, E\}$ dari pada $\{F, G, H, I, J\}$, maka $E$ tidak perlu pindah dari cluster $\{A, B, C, D, E\}$.

Dengan cara yang sama diperoleh pengelompokkan sebagai berikut:

$\mathrm{F} \longrightarrow$ jarak $\mathrm{F}$ lebih dekat ke cluster $\{\mathrm{F}, \mathrm{G}, \mathrm{H}, \mathrm{I}, \mathrm{J}\}$ dari pada ke $\{\mathrm{A}, \mathrm{B}, \mathrm{C}, \mathrm{D}, \mathrm{E}\}$, maka tidak terjadi perpindahan cluster.

$\mathrm{G} \longrightarrow$ Karena jarak $\mathrm{G}$ lebih dekat ke cluster $\{\mathrm{F}, \mathrm{G}, \mathrm{H}, \mathrm{I}, \mathrm{J}\}$ dari pada ke $\{A, B, C, D, E\}$, maka tidak terjadi perpindahan cluster.

$\mathrm{H} \longrightarrow$ Karena jarak $\mathrm{H}$ lebih dekat ke cluster $\{\mathrm{F}, \mathrm{G}, \mathrm{H}, \mathrm{I}, \mathrm{J}\}$ dari pada ke $\{A, B, C, D, E\}$, maka tidak terjadi perpindahan cluster.

$\mathrm{I} \longrightarrow$ Karena jarak I lebih dekat ke cluster $\{A, B, C, D, E\}$ dari pada ke $\{F, G, H, I, J\}$, maka perlu ada perpindahan cluster.

$\mathrm{J} \longrightarrow$ Karena jarak $\mathrm{J}$ lebih dekat ke cluster $\{F, G, H, I, J\}$ dari pada ke $\{A, B, C, D, E\}$, maka tidak terjadi perpindahan cluster.

Dari perhitungan diatas, dapat dillihat jarak yang terbentuk dari centroid awal yaitu cluster 1 \{A,B,D,E,I\} dan cluster yang ke 2 \{C,F,G,H,J\}. Sehingga masih terdapat cluster yang tidak menempati anggotanya, maka perlu untuk membentuk centroid baru.

Tabel 4 : Centroid Baru

\begin{tabular}{|c|c|c|}
\hline Cluster & $X_{1}$ & $X_{2}$ \\
\hline$\{A, B, D, E, I\}$ & $\frac{4+5+4+4+3}{5}=\frac{20}{5}=4$ & $\frac{2+3+1+3+2}{5}=\frac{11}{5}$ \\
\hline$\{C, F, G, H, J\}$ & $\frac{2+1+2+2+1}{5}=\frac{8}{5}$ & $\frac{2+1+0+2+1}{5}=\frac{6}{5}$ \\
\hline
\end{tabular}

Sehingga centroid baru yang terbentuk adalah $C_{1}=\left(4, \frac{8}{5}\right)$ dan $C_{2}=$ $\left(\frac{11}{5}, \frac{6}{5}\right)$. Selanjutnya menghitung kembali jarak antara setiap objek dengan centroid baru, dan masukkan hasilnya ke dalam cluster yang terdekat. Perhitungannya sebagai berikut 


$$
\begin{aligned}
& d^{2}(A,\{A, B, D, E, I\})=(4-4)^{2}+\left(2-\frac{11}{5}\right)^{2}=(0)^{2}+(-0,2)^{2}=0,04 \\
& d^{2}(A,\{C, F, G, H, J\})=\left(4-\frac{8}{5}\right)^{2}+\left(2-\frac{6}{5}\right)^{2}=(2,4)^{2}+(0,8)^{2}=6,4
\end{aligned}
$$

Karena jarak A lebih dekat dengan cluster $\{A, B, D, E, I\}$ dari pada $\{C, F, G, H, J\}$, maka $A$ tidak perlu pindah dari cluster $\{A, B, D, E, I\}$.

$d^{2}(B,\{A, B, D, E, I\})=(5-4)^{2}+\left(3-\frac{11}{5}\right)^{2}=(1)^{2}+(0,8)^{2}=1,64$

$d^{2}(B,\{C, F, G, H, J\})=\left(5-\frac{8}{5}\right)^{2}+\left(3-\frac{6}{5}\right)^{2}=(3,4)^{2}+(1,8)^{2}=14,8$

Karena jarak $B$ lebih dekat dengan cluster $\{A, B, D, E, I\}$ dari pada $\{C, F, G, H, J\}$, maka $B$ tidak perlu pindah dari cluster $\{A, B, D, E, I\}$.

$d^{2}(C,\{A, B, D, E, I\})=(2-4)^{2}+\left(2-\frac{11}{5}\right)^{2}=(-2)^{2}+(-0,2)^{2}=4,04$

$d^{2}(C,\{C, F, G, H, J\})=\left(2-\frac{8}{5}\right)^{2}+\left(2-\frac{6}{5}\right)^{2}=(0,4)^{2}+(0,8)^{2}=0,8$

Karena jarak $\mathrm{C}$ lebih dekat dengan cluster $\{\mathrm{C}, \mathrm{F}, \mathrm{G}, \mathrm{H}, \mathrm{J}\}$ dari pada $\{\mathrm{A}, \mathrm{B}, \mathrm{D}, \mathrm{E}, \mathrm{I}\}$, maka $\mathrm{C}$ tidak perlu pindah dari cluster $\{\mathrm{C}, \mathrm{F}, \mathrm{G}, \mathrm{H}, \mathrm{J}\}$.

$d^{2}(D,\{A, B, D, E, I\})=(4-4)^{2}+\left(1-\frac{11}{5}\right)^{2}=(0)^{2}+(-1,2)^{2}=1,44$

$d^{2}(D,\{C, F, G, H, J\})=\left(4-\frac{8}{5}\right)^{2}+\left(1-\frac{6}{5}\right)^{2}=(2,4)^{2}+(-0,8)^{2}=5,8$

Karena jarak $D$ lebih dekat dengan cluster $\{A, B, D, E, I\}$ dari pada $\{C, F, G, H, J\}$, maka $D$ tidak perlu pindah dari cluster $\{A, B, D, E, I\}$.

$d^{2}(E,\{A, B, D, E, I\})=(4-4)^{2}+\left(3-\frac{11}{5}\right)^{2}=(0)^{2}+(0,8)^{2}=0,64$

$d^{2}(E,\{C, F, G, H, J\})=\left(4-\frac{8}{5}\right)^{2}+\left(3-\frac{6}{5}\right)^{2}=(2,4)^{2}+(1,8)^{2}=9$

Karena jarak E lebih dekat dengan cluster $\{A, B, D, E, I\}$ dari pada $\{C, F, G, H, J\}$, maka $E$ tidak perlu pindah dari cluster $\{A, B, D, E, I\}$.

$\mathrm{F} \rightarrow$ Karena jarak $\mathrm{F}$ lebih dekat dengan cluster $\{\mathrm{C}, \mathrm{F}, \mathrm{G}, \mathrm{H}, \mathrm{J}\}$ dari pada $\{A, B, D, E, I\}$, maka $F$ tidak perlu pindah dari cluster $\{C, F, G, H, J\}$.

$\mathrm{G} \rightarrow \quad$ Karena jarak $\mathrm{G}$ lebih dekat dengan cluster $\{\mathrm{C}, \mathrm{F}, \mathrm{G}, \mathrm{H}, \mathrm{J}\}$ dari pada $\{A, B, D, E, I\}, \quad$ maka $G$ tidak perlu pindah dari cluster $\{C, F, G, H, J\}$.

$\mathrm{H} \rightarrow$ Karena jarak $\mathrm{H}$ lebih dekat dengan cluster $\{C, F, G, H, J\}$ dari pada $\{A, B, D, E, I\}$, maka $H$ tidak perlu pindah dari cluster $\{C, F, G, H, J\}$.

$\mathrm{J} \rightarrow$ Karena jarak $\mathrm{J}$ lebih dekat dengan cluster $\{\mathrm{C}, \mathrm{F}, \mathrm{G}, \mathrm{H}, \mathrm{J}\}$ dari pada $\{A, B, D, E, I\}$, maka J tidak perlu pindah dari cluster $\{C, F, G, H, J\}$. 
Terlihat dari proses diatas, tidak terjadi adanya perpindahan cluster dan setiap objek sudah menunjuk ke suatu kelompok dengan rataan terdekat, sehingga proses berhenti sampai disitu. Dan cluster akhir yang terbentuk adalah Cluster $1\{A, B, D, E, I\}$

Cluster $2\{C, F, G, H, J\}$

\subsection{Pembahasan}

Dari data hasil perhitungan diatas diperoleh untuk gejala penyakit yang terdapat jumlah paling besar atau $\geq 3$ adalah gejala penyakit dalam cluster $1:\{A, B, D, E, I\}$ (Gejala penyakit dapat dilihat pada tabel 1), seperti yang telah di asumsikan bahwa diagnosa penyakit dalam cluster 1 adalah gejala penyakit yang parah dan tidak dapat di sembuhkan lagi ginjal yang di miliki. Lalu kemudian pada cluster $2:\{C, F, G, H, J\}$ (Gejala penyakit dapat dilihat pada tabel 1) atau pasien yang memiliki gejala penyakit gagal ginjal $<3$, termasuk ke dalam diagnosa penyakit gagal ginjal yang masih dalam tahap yang masih dapat disembuhkan.

\section{KESIMPULAN}

Berdasarkan hasil penelitian yang telah dilakukan, dapat disimpulkan bahwa Algoritma KMeans dapat digunakan untuk mendiagnosa penyakit gagal ginjal kronis, dimana hasil penelitian menunjukkan bahwa dari 10 pasien, ada 5 pasien yang menderita penyakit gagal ginjal kronis dan 5 pasien lagi dengan diagnosa gagal ginjal yang masih dapat disembuhkan.

\section{DAFTAR PUSTAKA}

[1]. Doenges E, Marilynn, dkk. 1999. Rencana Asuhan Keperawatan : Pedoman Untuk Perencanaan dan Pendokumentasian Perawatan Pasien. Edisi 3. EGC. Jakarta.

[2]. Santoso, B. 2007. Data Mining: Teknik Pemanfaatan Data untuk Keperluan Bisnis. Graha IImu. Yogyakarta.

[3]. Sudoyo, Aru W, dkk. 2006. IImu Penyakit Dalam. Jilid 3. Edisi 4. Pusat Penerbitan Departemen IImu Penyakit Dalam Fakultas Kedokteran Universitas Indonesia. Jakarta.

[4]. Sukandar, Enday. 2006. Gagal Ginjal dan Panduan Dialisis. PPI FK UNPAD. Bandung. 